The Journal of Engineering and Exact Sciences - JCEC, Vol. 04 N. 02 (2018)

journal homepage: https://jcec.ufv.br

doi: https://doi.org/10.18540/jcecvl4iss2pp0196-0201

OPEN ACCESS - ISSN: 2527-1075

\title{
CARACTERIZAÇÃO DE REVESTIMENTO BIOPOLIMÉRICO VISANDO APLICAÇÃO EM EMBALAGENS CELULÓSICAS
}

\section{CHARACTERIZATION OF BIOPOLYMER COATING FOR APPLICATION IN CELLULOSIC PACKAGING}

\section{A. L. M. DOMINGOS ${ }^{1}$, A. C. M. PEREIRA ${ }^{1}$, A. P. R. NOLETTO ${ }^{2}$ e A. B. REIS ${ }^{3}$}

${ }^{1}$ BC\&T - Bacharelado em Ciência e Tecnologia, Universidade Federal dos Vales do Jequitinhonha e Mucuri, Diamantina, MG, Brasil.

${ }^{2}$ Instituto de Tecnologia de Embalagens - ITAL -Centro de Tecnologia de Embalagem para Alimentos-CETEA, Campinas-SP, Brasil.

${ }^{3}$ Universidade Federal dos Vales do Jequitinhonha e Mucuri - Departamento de Engenharia Química-Diamantina-MG, Brasil.

*Autor correspondente. Universidade Federal dos Vales do Jequitinhonha e Mucuri, Engenharia Química, Diamantina, MG, Brasil.

e-mail: arlete.reis@ict.ufvjm.edu.br(A.B.Reis).

\begin{tabular}{|c|}
\hline A R T I C L E I N F O \\
\hline $\begin{array}{l}\text { Article history: } \\
\text { Received: } 2017-11-15 \\
\text { Accepted: } 2018-03-22 \\
\text { Available online: } 2018-06-30\end{array}$ \\
\hline $\begin{array}{l}\text { palavras-chave } \\
\text { Biopolímeros } \\
\text { Quitosana } \\
\text { Amido } \\
\text { Revestimento } \\
\text { Embalagens Celulósicas. }\end{array}$ \\
\hline $\begin{array}{l}\text { keywords} \\
\text { Biopolymers } \\
\text { Chitosan } \\
\text { Starch } \\
\text { Coating } \\
\text { Celulosic Packaging }\end{array}$ \\
\hline
\end{tabular}

\begin{abstract}
A B S T R A C T
In order to achieve improvements in packaging performance, innovative materials based on renewable sources have been developed, mainly aiming at the total or partial substitution of the use of synthetic polymers as coatings of cellulosic packaging. The biopolymer chitosan, as well as starch, are the raw materials of interest, both holders of great application, both in food and feed, and in the packaging industry. Within this context, the present work had as objective, characterize sheets of paperboard coated with chitosan and starch based filmogenic solution. For that, analyzes of thickness, weight, Scanning Electron Microscopy (SEM), Water Vapor Permeability Rate (WVPR), Water Absorption (Cobb), where there were improvements in results when compared to samples of uncoated carton paper. Only the tensile strength analysis showed no significant changes.
\end{abstract}

\begin{abstract}
R E S U M O
No intuito de se obter melhorias no desempenho de embalagens, materiais inovadores a base de fontes renováveis vêm sendo desenvolvidos, visando sobretudo a substituição total ou parcial do uso de polímeros sintéticos como revestimentos de embalagens celulósicas. $O$ biopolímero quitosana, assim como o amido, são matérias primas de interesse, ambos detentores de grande aplicação, tanto na alimentação humana e animal, quanto na indústria de embalagens. No âmbito desse contexto, o presente trabalho teve como objetivo, caracterizar folhas de papel cartão revestidas com solução filmogênica à base de quitosana $e$ amido. Para tanto, foram realizadas análises de espessura, gramatura, Microscopia Eletrônica de Varredura (MEV), Taxa de Permeabilidade ao Vapor D’água (TPVA), Absorção D'água (Cobb), onde houveram melhorias nos resultados quando comparados com amostras de papel cartão sem revestimento. Somente a análise de resistência à tração, não apresentou alterações significativas.
\end{abstract}




\section{INTRODUCTION}

A indústria de embalagens, com vistas a desenvolver novos materiais, originários de fontes renováveis, baseada no interesse de melhorar a qualidade de seus produtos e do meio ambiente, bem como a crescente busca por sustentabilidade, tem impulsionado pesquisas utilizando como diferencial os biopolímeros. Sendo assim, a busca novas metodologias, com possibilidade de realização e custo efetivo que, além de manter a integridade do produto, garantam a qualidade, segurança (Ouattara et al., 2000) e confiança do consumidor (Aider, 2010).

No âmbito desse contexto, visando a redução do grande acúmulo de resíduos nas grandes cidades, pesquisas seguem no sentido do desenvolvimento de novas metodologias e processos de obtenção de embalagens que, em sua maioria desejam a substituição dos produtos sintéticos por materiais de origem biológicas e possivelmente reaproveitáveis, à exemplo, tempos os revestimentos poliméricos.

Os revestimentos à base de misturas poliméricas podem também atuar como veículo na incorporação de aditivos como agentes antioxidantes, antimicrobianos, flavorizantes, dentre outros, além de a integridade mecânica e/ou as características de manuseio do produto (Krochta e MulderJohnston, 1997).

Segundo Mali e Grossmann (2003), as macromoléculas biológicas mais estudadas para este fim são as proteínas e os polissacarídeos, polímeros capazes de formar matrizes contínuas que, através de diversas técnicas, podem ser produzidas como filmes e revestimentos comestíveis e/ou biodegradáveis.

A utilização de polímeros naturais na formação de embalagens flexíveis, como forma de garantir a sustentabilidade das mesmas, vem sendo intensamente estudada em âmbito mundial, visando a substituição total ou parcial dos polímeros sintéticos, principalmente devido ao problema ambiental de acúmulo de lixo de difícil degradação (Aider, 2010).

Geralmente utilizam-se dois tipos de biomoléculas na elaboração de filmes biodegradáveis, os hidrocolóides e os lipídios. Os hidrocolóides são polissacarídeos ou açúcares complexos formados por moléculas grandes que interagem com água e dependendo da quantidade de água disponível pode se comportar como um gel ou líquido. Polissacarídeos como amido, celulose, gomas ou proteínas (gelatina, glúten, zeína) por serem hidrofílicos apresentam uma pobre barreira à umidade, sendo essa propriedade compensada pela adição de lipídios, os quais apresentam uma boa barreira à umidade (Tharanathan, 2003).

Os polissacarídeos por serem polímeros naturais que tanto agem como depósito de energia nas plantas (amido) e animais (glicogênio), como exercem funções estruturais na parede celular de plantas (celulose, pectina) ou no exoesqueleto de insetos e crustáceos (quitina) (Nelson e Cox, 2000).

Dentre os biopolímeros comumente utilizados nas indústrias de embalagens pode-se citar a quitosana, devido a sua biodegradabilidade, por ser originária de fontes renováveis, ser capaz de formar filmes flexíveis e resistentes, com barreira eficiente a oxigênio, além de atividade antimicrobiana (Jo et al., 2001; Chen et al., 2002; Quintavalla et al., 2002;).

Numerosas aplicações de quitosana foram sugeridas, sendo que, os tópicos mais estudados são: remoção de proteínas, remoção de íons metálicos, tratamento de efluentes, aplicações na indústria têxtil e de papel (Peter, 2002), podendo também ser usada como filme protetor na aplicação de embalagens (Kittur et al., 1998).

Além da quitosana, o amido também vem sendo estudado por muitos autores visto que o mesmo possui características atraentes no que diz respeito a embalagens, pois é uma matéria-prima abundante que permite o desenvolvimento de produtos recicláveis e tem gerado muitas pesquisas enfatizando o seu uso como bioplástico (Van Soest e Essers, 1997; Della Valle et al., 1998; Hulleman et al., 1998; Forssell et al., 1999). Estas características tem despertado um interesse acentuado no mercado de polímeros convencionais através da sua incorporação em misturas poliméricas.

Dentro dessa perspectiva, o presente trabalho teve como objetivo avaliar a aplicação de revestimento à base de quitosana e amido, em folhas de papel cartão, visando aplicações futuras no setor de embalagens celulósicas. Tal avaliação se deu por intermédio de possíveis melhorias nas propriedades mecânicas e de barreira em folhas de papel cartão revestidas com solução filmogênica à base de quitosana e amido. Para tanto, foram realizadas análises de espessura, gramatura, Taxa de Permeabilidade ao Vapor D’água (TPVA), Microscopia Eletrônica de Varredura (MEV), Capacidade de Absorção de àgua (Cobb) e Resistência à Tração.

\section{MATERIAIS E MÉTODOS}

\subsection{Materiais}

Para a produção da solução filmogênica utilizou-se quitosana (Polymar), amido de milho (comercial), ácido acético Glacial (Synth) e glicerol (Synth) como plastificante. O revestimento foi distribuído em papel cartão de gramatura $277 \mathrm{~g} / \mathrm{m}^{2}$ fornecido pela empresa Klabin Papéis Monte Alegre.

\subsection{Métodos}

A metodologia apresentada a seguir descreve a produção da solução filmogênica e a aplicação do revestimento no papel cartão assim como os métodos utilizados para o desenvolvimento do presente trabalho. Para a realização dos ensaios, os corpos-de-prova foram previamente condicionados a $23 \pm 1^{\circ} \mathrm{C}$ e $50 \pm 2 \%$ UR , conforme a Norma NBR NM ISO 187(ABNT, 2000).

Preparo da solução filmogênica: A metodologia consistiu primeiramente em dispersar o amido e a quitosana em solução aquosa ácida nas concentrações de 1,0\% e posteriormente de 2,0\%. Adicionando-se ácido acético estequiometricamente, de acordo com o grau de acetilação da quitosana, sendo portanto equivalente a $1,0 \%$ (em massa) e $0,5 \%$ de plastificante. A solução foi submetida sob agitação contínua por 60 minutos, a temperatura de $\pm 50^{\circ} \mathrm{C}$. 
Aplicação da solução nas folhas de papel cartão: A aplicação da solução filmogênica nas folhas de papel cartão foi realizada com o auxílio de uma barra extensora em aço inox de 40,0 $\mu \mathrm{m}$ (TKB Ericken, Brasil). As folhas de papel cartão foram fixadas num suporte metálico e em seguida foram distribuídos 4,0 mL de solução filmogênica, donde foi possível se obter a distribuição de $0,752 \mathrm{ml}_{\text {solução }} / \mathrm{mm}^{2}$ e, em seguida as folhas de papel cartão já revestidas foram submetidas ao processo de secagem em estufa à $100^{\circ} \mathrm{C}$ por um período igual a 90 segundos. Ao final do processo de aplicação dos diferentes tipos de revestimento obteve-se duas formulações, intituladas de PQA1 e PQA2 (Tabela 1).

\begin{tabular}{|c|c|c|c|}
\hline Sigla & PSR & PQA1 & PQA2 \\
\hline $\begin{array}{c}\text { Composição } \\
(\%)\end{array}$ & & $\begin{array}{c}1,0 \% \text { de } \\
\text { Quitosana } \\
1,0 \% \text { de Amido } \\
0,5 \% \text { de } \\
\text { glicerol }\end{array}$ & $\begin{array}{c}1,0 \% \text { de } \\
\text { Quitosana } \\
2,0 \% \text { de Amido } \\
0,5 \% \text { de glicerol }\end{array}$ \\
\hline Amostra & $\begin{array}{l}\text { Papel } \\
\text { cartão sem } \\
\text { revestir }\end{array}$ & $\begin{array}{l}\text { Papel cartão } \\
\text { revestido com } \\
\text { solução } \\
\text { filmogênica de } \\
\text { quitosana e } \\
\text { amido }\end{array}$ & $\begin{array}{l}\text { Papel cartão } \\
\text { revestido com } \\
\text { solução } \\
\text { filmogênica de } \\
\text { quitosana e } \\
\text { amido }\end{array}$ \\
\hline
\end{tabular}

Espessura: A espessura das amostras foi determinada de acordo com a norma NBR NM-ISO 534 (ABNT, 2000). Foi utilizado um micrômetro da marca Lorentzen \& Wettre, com área de contato igual à $200 \pm 10 \mathrm{~mm}^{2}$ e pressão exercida sobre a amostra de $100 \pm 10 \mathrm{kPa}$. Foram avaliados 5 corpos-de-prova por amostra. Os resultados foram expressos em micras $(\mu \mathrm{m})$.

Gramatura: Para obtenção da gramatura das amostras, os corpos-de-prova foram cortados no tamanho 130 x $130 \mathrm{~mm}$ com auxílio de dispositivo padrão e pesados em balança analítica Mettler modelo AE 163. A metodologia descrita foi baseada na norma NBR NM ISO 536 (ABNT, 2000). Foram avaliados 10 corpos-de-prova para cada amostra analisada. Os resultados foram expressos em $\mathrm{g} / \mathrm{m}^{2}$.

MEV-Microscopia Eletrônica de Varredura: A análise de Microscopia Eletrônica de Varredura foi realizada no Instituto de Química da UFVJM-Universidade Federal dos Vales do Jequitinhonha e Mucuri-Campus JK-Diamantina-MG. As amostras foram cortadas com estilete nas dimensões de $1 \mathrm{~cm} x$ $1 \mathrm{~cm}$, submetidas a um banho de ouro e, em seguida, foram analisadas utilizando o equipamento MEV de bancada da marca Shimatzu.

\section{Propriedade de Barreira}

PVA - Taxa de Permeabilidade ao Vapor D’Água: Os A taxa de permeabilidade ao vapor d'água foi determinada para a condição $23^{\circ} \mathrm{C} / 75 \%$ UR por meio do método gravimétrico, baseado na Norma ASTM E 96/E 96 M-5 (ASTM, 1996). Esse método se baseia no aumento de peso de um material higroscópio (cloreto de cálcio anidro), colocado no interior de uma cápsula de alumínio e isolado do ambiente de condicionamento pelo material cuja TPVA se deseja conhecer. A área efetiva (circunferência) de permeação de cada corpo-de-prova foi de
$50 \mathrm{~cm}^{2}$. O ganho de peso foi quantificado em balança analítica Mettler, modelo AT 400, com resolução de $10^{-4} \mathrm{~g}$. O condicionamento foi feito em câmara Patra, utilizando a solução salina de cloreto de sódio obtendo a condição interna de $23^{\circ} \mathrm{C} / 75 \% \mathrm{UR}$.

As amostras foram avaliadas em triplicata, os resultados foram expressos em ( $\mathrm{g}_{\text {água }} / \mathrm{m}^{2}$.dia) e calculados de acordo com a equação 1 .

$$
T P V A=\frac{\Delta m}{\Delta t} \times \frac{1}{A}
$$

Onde: TPVA = taxa de permeabilidade ao vapor d'água (gágua $/ \mathrm{m}^{2}$.dia); $\Delta \mathrm{m}=$ massa de água absorvida pelo material higroscópico no tempo "t" (g); $\mathrm{A}=$ área de corpo-de-prova exposta $\left(\mathrm{m}^{2}\right) ; \Delta \mathrm{t}=$ tempo de permeação (dias).

Capacidade de absorção d'água (Método Cobb): A capacidade de absorção de água foi determinada de acordo com a Norma NBR NM ISO 535 (ABNT, 1999). O ganho de peso foi acompanhado em balança analítica Mettler AE 163 e os resultados foram expressos em $\mathrm{g} / \mathrm{m}^{2}$. A absorção foi calculada de acordo com a equação 2 :

$$
A b s=\left(M_{f}-M_{i}\right) \times 100
$$

Onde: Abs = absorção de água $\left(\mathrm{g} / \mathrm{m}^{2}\right) ; \mathrm{M}_{\mathrm{i}}=$ massa inicial do corpo-de-prova; $\mathrm{M}_{\mathrm{f}}=$ massa final do corpo-de-prova.

Para a realização do ensaio, as amostras foram cortadas nas dimensões de $130 \mathrm{~mm}$ x $130 \mathrm{~mm}$, totalizando 20 corpos-deprova, dos quais 10 representam a parte interna (onde não houve aplicação de revestimento) e o restante, a parte externa (onde houve aplicação de revestimento). As amostras foram expostas em contato direto com água por 120 segundos e pesadas imediatamente.

\section{Propriedade Mecânica}

Resistência à Tração: Baseada na metodologia descrita na norma NBR NM-ISO 1924-2 (ABNT, 2001) os corpos-de-prova com largura de $15,0 \pm 0,1 \mathrm{~mm}$ e $200 \mathrm{~mm}$ de comprimento foram cortados nas duas direções, longitudinal (direção de fabricação do papel-sentido das fibras) e transversal (direção perpendicular à direção de fabricação). $\mathrm{O}$ ensaio foi realizado em máquina universal de ensaio marca Instron modelo 5500R, usando célula de carga de $1 \mathrm{kN}$ e velocidade de afastamento das garras de $20 \mathrm{~mm} / \mathrm{min}$. A distância inicial entre as garras usada foi de 180mm. A resistência à tração foi expressa em kgf/15mm. Foram feitas 10 repetições para cada amostra.

\section{RESULTADOS}

As análises foram realizadas em parceria com o CETEACentro de Tecnologia em Embalagens localizado em CampinasSão Paulo. Todos os testes seguiram as normas da ABNT. Os resultados obtidos foram verificados pelo teste de Tukey, comparando as amostras entre si, utilizando o programa Statistica versão 7.0. 
Análise de Espessura: Os resultados da análise da espessura, das amostras com e sem revestimento, foi obtido através de 5 determinações (Tabela 2).

Tabela 2- Resultados da análise de espessura $(\mu \mathrm{m})$.

\begin{tabular}{cccc} 
Amostras & Média & $\begin{array}{c}\text { Intervalo } \\
\text { de Variação }\end{array}$ & CV(\%) \\
PSR & $407^{\mathrm{a}}$ & $400-410$ & 1 \\
PQA1 & $422^{\mathrm{b}}$ & $419-424$ & 0 \\
PQA2 & $424^{\mathrm{b}}$ & $419-427$ & 1 \\
\hline CV: coeficiente de variação = (desvio padrão/média) x 100. Nota: letras \\
diferentes (a,b) na mesma coluna representam diferenças significativas \\
(p<0,05) entre as médias obtidas pelo teste de Tukey.
\end{tabular}

Conforme ilustra a Tabela 2, amostras revestidas aumentaram a espessura quando comparadas com a amostra sem revestimento. Contudo entre as amostras revestidas, não houve diferença estatisticamente significativa. De acordo com Mali et al. (2004), este parâmetro influencia largamente as propriedades mecânicas, principalmente a força na perfuração e a permeabilidade ao vapor d'água de filmes hidrofílicos.

Gramatura: No ensaio de gramatura foram realizadas 10 determinações para cada amostra. Os resultados estão descritos na Tabela 3 .

Tabela 3 - Resultados da análise de gramatura $\left(\mathrm{g} / \mathrm{m}^{2}\right)$.

\begin{tabular}{c|c|c|c}
\hline Amostras & Média & $\begin{array}{c}\text { Intervalo } \\
\text { de Variação }\end{array}$ & CV(\%) \\
PSR & $282,0^{\mathrm{a}}$ & $279,8-284,6$ & 0,5 \\
PQA1 & $284,6^{\mathrm{b}}$ & $282,2-286,8$ & 0,5 \\
PQA2 & $286,2^{\mathrm{b}}$ & $283,0-287,9$ & 0,5 \\
\hline CV: coeficiente de variação $=($ desvio padrão/média) x 100. Nota: letras \\
diferentes (a,b) na mesma coluna representam diferenças significativas \\
(p<0,05) entre as médias obtidas pelo teste de Tukey.
\end{tabular}

Os resultados obtidos mostram que os revestimentos aumentaram a gramatura do papel, visto que as amostras revestidas apresentaram diferença estatisticamente significativa quando comparadas com a amostra sem revestimento. A amostra PQA2 apresentou maior gramatura aplicada do que a amostra PQA1, o que pode ser explicado devido ao maior teor de sólidos aplicados, para as amostras contendo $2 \%$ de amido $\left(1,50 \mathrm{~g} / \mathrm{m}^{2}\right)$ ao passo que, a amostras PQA1 possuía em sua composição $1 \%$ de amido $\left(0,75 \mathrm{~g} / \mathrm{m}^{2}\right)$. Além disso, pode-se observar que mesmo não apresentando diferenças estatisticamente significativas na espessura das amostras revestidas (PQA1 e PQA2), a gramatura das amostras apresentou aumento gradativo, o que pode ser explicado pelas interações moleculares entre o amido e a quitosana, ou seja, mesmo aumentando a porcentagem de amido no revestimento ainda existia a possibilidade de mais interações entre os materiais.

Segundo Sarantópoulos (2002), o ensaio de gramatura é uma determinação útil para avaliação e controle de qualidade, pois permite obter rapidamente informações sobre o desempenho de um material de embalagem.

Análise de Microscopia Eletrônica de Varredura (MEV): A análise de microscopia eletrônica de varredura oferece vantagens nas investigações tanto de superfícies ásperas quanto lisas, desde vistas planas, lateral ou à fraturas particulares. No presente trabalho, foram realizadas análises de vista plana, nas amostras PQR, PQA1e FQA2, ambas nas ampliações 200, 500 e 1000vezes.

Conforme ilustra a Figura 1, na amostra PQA1, foi possível visualizar a formação de grumos, devido à pequena quantidade de amido. $\mathrm{O}$ que foi evidenciado na amostra PQA2, o que pode ser devido ao fato de as soluções não ter sido homogeneizada em altas rotações (Figura 1). As amostras PQA1 e PQA2, contendo $0,75 \mathrm{~g} / \mathrm{m}^{2}$ e $1,50 \mathrm{~g} / \mathrm{m}^{2}$ de sólidos totais, respectivamente, em comparação com as amostras PSR.

Análise de Absorção de Água - Método Cobb : Os resultados obtidos pelo teste de absorção de água mostraram que todas as amostras apresentaram diferenças estatisticamente significativas. Isso pode ser explicado pelo fato de todas as amostras apresentarem um aumento na espessura e na gramatura, quanto maior a espessura e gramatura, menor foi a absorção de água. Além disso, a aplicação da maior quantidade de revestimento serviu como suporte e/ou uma possível barreira às possíveis interações com a água. As amostras RQA1 e RQA2 apresentaram redução da ordem de 15 e 19\%, respectivamente, quando comparadas com a amostra PSR (Tabelas 4 e 5).

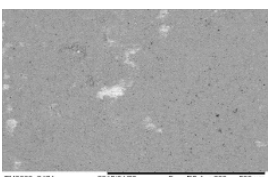

(a) PSR (200x)

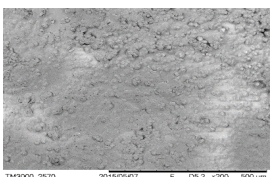

(d) PQA1 (200x)

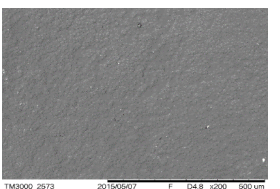

(g) PQA2 (200x)

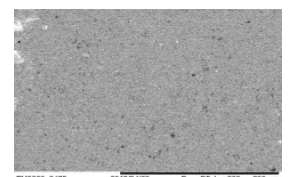

(b) PSR (500x)

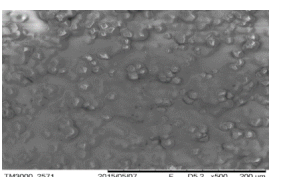

(e) PQA1 (500x)

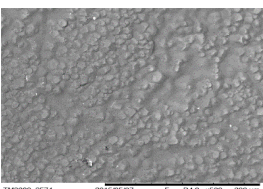

(h) PQA2 $(500 x)$

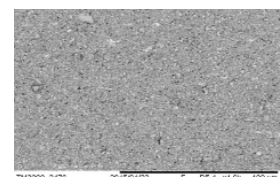

(c) PSR (1000x)
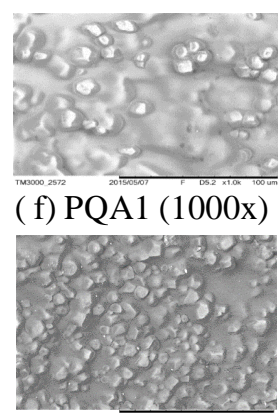

(i) PQA2 $(1000 x)$
Figura 1 - Análises MEV-Vista Plana amostras: PSR (a), (b), (c) ; PQA1 (d), (e), (f) ; PQA2 (g), (h), (i). Ambas nas ampliações 200x, 500x e 1000x.

Tabela 4 - Resultados da análise de absorção de água $\left(\mathrm{g} / \mathrm{m}^{2}\right)$ - Externo.

\begin{tabular}{c|c|c|c|} 
Amostras & Média & $\begin{array}{c}\text { Intervalo } \\
\text { de Variação }\end{array}$ & $\mathbf{C V}(\%)$ \\
PSR & $27^{\mathrm{a}}$ & $27-28$ & 1,50 \\
PQA1 & $23^{\mathrm{b}}$ & $22-24$ & 3,45 \\
PQA2 & $22^{\mathrm{c}}$ & $21-22$ & 1,12 \\
\hline
\end{tabular}

Nota: letras diferentes $(\mathrm{a}, \mathrm{b}$ e c) na mesma coluna representam diferenças significativas $(\mathrm{p}<0,05)$ entre as médias obtidas pelo teste de Tukey. CV: coeficiente de variação $=($ desvio padrão/média $) \times 100$.

Considerando a literatura, o amido e a quitosana são materiais hidrofílicos, contradizendo os resultados obtidos, donde podemos afirmar que a interação entre os materiais formou uma pequena barreira, portanto houveram diferenças estatisticamente significativas. 
Tabela 5 - Resultados da análise de Absorção de Água $\left(\mathrm{g} / \mathrm{m}^{2}\right)$ - Interno

\begin{tabular}{c|c|c|c} 
Amostras & Média & $\begin{array}{c}\text { Intervalo } \\
\text { de Variação }\end{array}$ & $\mathbf{C V}(\boldsymbol{\%})$ \\
PSR & $38^{\mathrm{a}}$ & $36-39$ & 3,11 \\
PQA1 & $38^{\mathrm{a}}$ & $37-39$ & 1,92 \\
PQA2 & $35^{\mathrm{b}}$ & $35-36$ & 2,01 \\
\hline Nota: letras diferentes (a, b e c) na mesma coluna representam diferenças \\
significativas (p<0,05) entre as médias obtidas pelo teste de Tukey. CV: \\
coeficiente de variação = (desvio padrão/média) x 100.
\end{tabular}

Utilizando o teste de Tukey foi possível concluir que as amostras PSR e PQA1 não apresentaram diferenças estatisticamente significativas, a amostra PQA2 apresentou redução da ordem de $7,90 \%$. Donde podemos afirmar que a interação de uma maior quantidade de amido juntamente com a quitosana formou uma pequena barreira. Em contrapartida, a ausência de diferença entre as amostras PSR e PQA1 pode ser explicada devido a possíveis erros no acondicionamento das amostras, visto que a parte interna das mesmas não foi revestida, ou pelo fato do revestimento ter afetado a parte interna. A última afirmação é uma hipótese, onde mais testes deverão ser feitos para comprová-la.

A capacidade de absorção de água das folhas de papel cartão está diretamente relacionada com as propriedades mecânicas da embalagem. A absorção de umidade reduz as propriedades mecânicas, ocasionando o colapso das caixas durante o armazenamento e a distribuição (Rhim et al., 2006). As folhas de papel são formadas por fibras celulósicas, estas por sua vez, têm características hidrofílicas e quando em contato com umidade formam ligações de hidrogênio com moléculas de água, reduzindo a resistência e rigidez.

A absorção de água do papel é um padrão que mede a capacidade das capas (internas e externas do material) de absorverem água quando expostas a um contato direto por um tempo determinado. Segundo Noletto (2010), um baixo valor de absorção significa uma maior dificuldade de penetração de água no papel, impedindo a perda de resistência mecânica do material. Valores de absorção de água baixos são geralmente necessários em embalagens que serão usadas na estocagem de produtos refrigerados e podem estar sujeitas a condensação de água em suas superfícies internas e externas.

Taxa de Permeabilidade ao Vapor D’Água- TPVA : O contato de um produto e de sua embalagem com a umidade pode levar a diversos tipos de reações dos mesmos, de perdas de propriedades mecânicas à perda de características como sabores, odores e textura.

A determinação da quantidade máxima de umidade que pode permear através de uma embalagem sem tornar o produto inaceitável para o consumo é fundamental para a especificação de embalagens para produtos sensíveis ao ganho de umidade (Sarantópoulos, 2002) . No presente trabalho, as análises de TPVA foram realizadas em triplicata, à $23^{\circ} \mathrm{C}$ e $75 \% \mathrm{UR}$, nas amostras PSR, PQA1 e PQA2, conforme ilustra a Tabela 6.
Tabela 6 - Resultados da análise de TPVA (gágua.m².2 dia $\left.{ }^{-1}\right)$.

\begin{tabular}{c|c|c|c|}
\hline Amostras & Média & $\begin{array}{c}\text { Intervalo } \\
\text { De Variação }\end{array}$ & $\mathbf{C V ( \% )}$ \\
PSR & $500^{\mathrm{a}}$ & $471-496$ & 6,30 \\
PQA1 & $431^{\mathrm{b}}$ & $411-422$ & 1,40 \\
PQA2 & $417^{\mathrm{b}}$ & $415-453$ & 4,50 \\
\hline
\end{tabular}

Nota: letras diferentes $(\mathrm{a}, \mathrm{b}$ e c) na mesma coluna representam diferenças significativas $(\mathrm{p}<0,05)$ entre as médias obtidas pelo teste de Tukey. CV: coeficiente de variação $=($ desvio padrão/média $) \times 100$.

A permeabilidade ao vapor d'água das amostras com revestimento foi menor quando comparada com a amostra sem revestimento. Pela lei de difusão de Fick e a lei de sorção de Henry, a TPVA deve variar com o inverso da espessura do filme, sendo assim, a diminuição do TPVA das amostras revestidas pode ser explicada pela diferença de espessura, com pode ser observado pela tabela de espessura (Tabela 2), pelo aumento relativo da gramatura e pelas interações moleculares entre o amido e a quitosana, que de certa forma, atuaram como mais uma barreira para o papel. Mesmo tendo os resultados, apresentado uma alta permeabilidade devido à higroscopicidade comum aos materiais celulósicos, neste caso, às folhas de papel cartão, pode-se dizer que os revestimentos aplicados apresentaram uma redução da ordem de $13,8 \%$ para as amostras PQA1 e 16,6\% para as amostras PQA2, ambas comparadas com as amostras PSR.

Resistência a Tração: A capacidade de o papel resistir a forças externas é um parâmetro importante quando se trata de embalagens. Além da composição, o modo de produção e a aplicação de revestimentos podem influenciar nos resultados das propriedades mecânicas. A Tabela 7 , expressa os resultados obtidos no ensaio de resistência à tração, tanto na direção de fabricação (DF), quanto na direção transversal (DT).

Tabela 7- Resultados do ensaio de Resistência à Tração (kgf/15mm).

\begin{tabular}{c|c|c|c|c} 
Amostra & Direção & Média & $\begin{array}{c}\text { Intervalo } \\
\text { de } \\
\text { Variação }\end{array}$ & $\mathbf{C V}(\boldsymbol{\%})$ \\
\multirow{2}{*}{ PSR } & DF & $26^{\mathrm{a}}$ & $22-28$ & 8,73 \\
& DT & $15^{\mathrm{a}}$ & $15-16$ & 1,55 \\
\hline \multirow{2}{*}{ PQA1 } & DF & $26^{\mathrm{a}}$ & $25-27$ & 4,11 \\
& DT & $15^{\mathrm{a}}$ & $14-16$ & 6,34 \\
\hline \multirow{2}{*}{ PQA2 } & DF & $26^{\mathrm{a}}$ & $24-27$ & 5,45 \\
& DT & $16^{\mathrm{a}}$ & $15-17$ & 6,47 \\
\hline
\end{tabular}

O ensaio de resistência à tração, pelo teste de Tukey, mostrou que as amostras não apresentaram diferenças estatisticamente significativas, tanto na direção de fabricação quanto na direção transversal, mesmo quando comparadas com a amostra sem revestimento.

Partindo do princípio de que, as folhas de papel são formadas por fibras celulósicas, possuindo, portanto, características hidrofílicas, ou seja, quando em contato com umidade formam ligações de hidrogênio com moléculas de água, reduzindo desta forma características importantes como resistência e rigidez, no presente trabalho o fato de a análise de resistência à tração não ter apresentado diferenças estatisticamente significativas, implica em afirmar que a 
aplicação de revestimentos à base de quitosana e amido não iriam alterar características essenciais à embalagem.

\section{DISCUSSÃO}

A obtenção de um revestimento para aplicação em embalagem celulósica, aliado ao interesse em manter e/ou tornar a embalagem o mais biodegradável possível, poderia atuar como coadjuvante no processo de diminuição de resíduos, e produtos de forma ambientalmente correta. Partindo desse pressuposto, a partir de análises de caracterização do revestimento à base de quitosana e amido, quando aplicado em folhas de papel cartão, resultou, em sua maioria em positiva nas análises de gramatura, espessura, absorção de água e TPVA.

A aplicação do revestimento aumentou significativamente a gramatura e espessura do papel. A amostra PQA2 apresentou uma gramatura aplicada maior que as demais, devido à aplicação de um maior teor de sólidos. O ensaio de absorção de água apresentou redução da ordem de 15 e 19\%, das amostras PQA1 e PQA2, respectivamente, quando comparadas com a amostra PSR. Sendo assim, pode-se concluir que o revestimento aplicado influenciou neste ensaio.

A aplicação do revestimento também influenciou na TPVA, podendo ser observada redução da ordem de 13,8\% para as amostras PQA1 e 16,6\% para as amostras PQA2, quando comparadas com as amostras PSR. No ensaio de resistência à tração, o revestimento aplicado não influenciou significativamente nos resultados obtidos.

\section{CONCLUSÃO}

De modo geral, o revestimento aplicado influenciou o desempenho das folhas de papel cartão tendo como base comparativa as folhas sem revestimento. A amostra que continha maior quantidade de amido (PQA2) apresentou melhores resultados, logo com uma maior quantidade de amido obteve-se melhor barreira à umidade.

\section{A G R A D E C I M E N T O S}

Os autores agradecem o apoio do ITAL - Instituto de Tecnologia de Alimentos, ao CETEA-Centro de Tecnologia de Embalagens para Alimentos, à empresa Klabin S/A LMMA patrocinado pela FAPEMIG (CEX-112-10), SECTES / MG e RQ-MG (FAPEMIG: CEX-RED-00010-14).

\section{R E FE R E N C I A S}

AIDER, M. Chitosan application for active bio-based films production and potential in the food industry. Food Science and Technology, v.43, p.837-842,2010.

American Society for Testing and Materials - ASTM - Standard test methods for water vapor transmission of materials. ASTM E 96/E 96 M-05. Philadelphia: ASTM, 1996. 6p. Campinas, v. 05, n. 01, p. 7 - 9, 1993.

American Society for Testing and Materials- ASTM - Standard test methods for water vapor transmission of materials. ASTM E 96/E 96 M-05. Philadelphia: ASTM, 1996. 6p. Campinas, v. 05, n. 01, p. 7 - 9, 1993.

Associação Brasileira de Normas Técnicas NBR NM ISSO 187: Papel, cartão e pastas celulósicas - atmosfera normalizada para condicionamento e ensaio e procedimento de controle da atmosfera e condicionamento das amostras, 10p. Rio de Janeiro, 2000.
Associação Brasileira de Normas Técnicas. NBR NM-ISO 1924-2: Papel e cartão: determinação das propriedades de tração: parte 2: método da velocidade constante de alongamento. Rio de Janeiro, 2001. 4p.

Associação Brasileira de Normas Técnicas. NBR NM-ISO 534: Papel e cartão: determinação da espessura e da densidade aparente de uma única folha ou de um maço. Rio de Janeiro, 2000. 2p.

Associação Brasileira de Normas Técnicas. NBR NM - ISO 535: Papel e cartão: determinação da capacidade de absorção de água: método Cobb. Rio de Janeiro, 1999. 5p.

Associação Brasileira de Normas Técnicas. NBR NM - ISO 536: Papel e cartão: determinação da gramatura. Rio de Janeiro, 2000b. 1p.

CHEN, X. G.; ZHENG, L.; WANG, Z.; LEE, C. Y.; PARK, H. J. Molecular affinity and permeability of different molecular weight chitosan membranes. Journal of Agricultural and Food Chemistry, v. 50, p. 5915-5918, 2002.

DELla VALLE, G.; BULEON, A.; CARREAU, P. J.; LAVOIE, P. A.; VERGNES, B. Relationship between structure and viscoelastic behavior of plasticized starch. Journal of Rheology, v. 42, p. 507-525, 1998.

FORSSELL, P.; HULLEMAN, S. H. D.; MYLLÄEINEN, P. J.; MOATES, G. K.; PARKER, R. Ageing of rubbery thermoplastic barley and oat starches. Carbohydrate Polymers, v. 39, p. 43-51, 1999.

HULLEMAN, S. H. D.; JANSSEN, F. H. P.; Feil, H. The role of water during plasticization of native starches.Polymer, v. 39, n. 10, p. 2043-2048, 1998.

JO, C.; LEE, J. W.; LEE, K. H.; BYUN, M. W. Quality properties of pork sausage prepared with water-soluble chitosan oligomer. Meat Science, v. 59, p. 369-375, 2001 .

KITTUR, F. S.; KUMAR, K. R.; THARANATHAN, R.N. Funcional packaging properties of chitosan films, Z. ebensm Unters Forsch A. v.206, p. 4447, 1998.

KROCHTA, J. M.; MULDER-JOHNSTON, C. D. Edible and biodegradable polymer films: challenges andopportunities. Food Technology, v, 51, n.2, p. 61-74, 1997.

MALI, S.; GROSSMANN, M.V.E. Effects of yam starch films on storability and quality of fresh strawberries. Journal of Agricultural and Food Chemistry, Easton, v.51, v.24, p.7055-7011, 2003.

MALI, S., KARAM, L. B.; RAMOS, L. P.; GROSSMANN, M. V. E. Relationships among the composition and physicochemical properties of starches with the characteristics of their films. Carbohydrate Polymers, v. 52, p. 7720-7725, 2004.

NELSON, L. N., COX, M. M. Lehninger Principles of Biochemistry, 3 ed. New York: Worth Publishers, 2000

NOLETTO, A. P. R. Embalagens de Papelão Ondulado: Propriedades e Avaliação da Qualidade. Campinas, ITAL/CETEA, 2010. 62-64p

PETER, M. G. Chitin and chitosan in Fungi chitin and chitosan fron animal sources. University of Potsdam, Institute of Organic Chemistry and Structure Analysis, Wiley-UCH, Weinheim, vol. 6, 2002.

OUATTARA, B.; SIMARD, R. E.; PIETTE, G.; BEGIN, A.; HOLLEY, R. A. Diffusion of acetic and propionic acids from chitosan-based antimicrobial packaging films. Journal of Food Science, v. 65, p. 768$773,2000$.

QUINTAVALLA, S.; VICINI, L. Antimicrobial food packaging in meat industry. Meat Science, v. 62, p. 373-380, 2002.

RHIM J W, LEE J H, HONG SI. 2006. Water resistance and mechanical properties of biopolymer (alginate and soy protein) coated paper boards. Lebensm Wiss Technol 39:806-13.

SARANTÓPOULOS, C.I.G.L.; OLIVEIRA, L.M.; PADULA, M.; COLTRO, L.; ALVES, R.M.V.; GARCIA, E.E.C. Embalagens plásticas flexíveis - principais polímeros e avaliação de propriedades. Campinas, ITAL/CETEA, 2002. 267p.

THARANATHAN, R. N. Biodegradable films and composite coatings: past, present and future. Trends in Food Science and Technology, v. 14, p. 71-78, 2003.

VAN SOEST, J. J. G.; Essers, P. Influence of amylose-amylopectin ratio on properties of extruded starch plastic sheets. Journal of Macromolecular Science Part A: Pure and Applied Chemistry, v. 34, n. 9 , p. $1665-1689,1997$. 